\title{
Phytochemical Screening and Antioxidant Activities of Some Selected Medicinal Plants Used for Malaria Therapy in Southwestern Nigeria
}

\author{
GA Ayoola ${ }^{1 *}$, HAB Coker ${ }^{1}$, SA Adesegun ${ }^{2}$, AA Adepoju-Bello1, \\ K Obaweya ${ }^{1}$, EC Ezennia', TO Atangbayila ${ }^{1}$ \\ ${ }^{1}$ Department of Pharmaceutical Chemistry, ${ }^{2}$ Department of Pharmacognosy, Faculty of Pharmacy, University of \\ Lagos, Lagos, Nigeria
}

\begin{abstract}
Purpose: Oxidative stress has been shown to play an important role in the development of anaemia in malaria. Indeed, increase in total antioxidant status has been shown to be important in recovery from malaria. The antioxidant activities of four medicinal plants traditionally used in the treatment of malaria in southwestern Nigeria were determined.

Methods: The ethanolic extracts of the leaves of Carica papaya Linn. [Caricaceae] , stem bark of Magnifera indica Linn. [Anacardiaceae], leaves of Psidium guajava Linn. [Myrtaceae] and the leaves of Vernonia amygdalina Del. [Compositae], were used in the present study. The plant parts commonly used in the locality in malaria therapy were employed in this study. The plants were screened for the presence of phytochemicals and, their effect on 2,2-Diphenyl-1-picryl-hydrazyl radical (DPPH) was used to determine their free radical scavenging activity.

Results: Phytochemical screening of the plants showed the presence of flavonoids, terpenoids, saponins, tannins and reducing sugars. M. indica did not contain cardiac glycosides and alkaloids while, $P$. guajava also showed the absence of alkaloids and anthraquinones. Anthraquinones was similarly absent from V. amygdalina. Concentrations of the plant extracts required for $50 \%$ inhibition of DPPH radical scavenging effect $\left(I C_{50}\right)$ were recorded as $0.04 \mathrm{mg} / \mathrm{ml}, 0.313 \mathrm{mg} / \mathrm{ml}, 0.58 \mathrm{mg} / \mathrm{ml}, 2.30 \mathrm{mg} / \mathrm{ml}$ and $0.054 \mathrm{mg} / \mathrm{ml}$ for P. guajava, M. Indica, C. papaya, V. amygdalina and Vitamin C, respectively.

Conclusion: All the plants showed potent inhibition of DPPH radical scavenging activity, $P$. guajava being the most potent. The free radical scavenging (antioxidant) activities of these plants probably contribute to the effectiveness of the above plants in malaria therapy.
\end{abstract}

Key words: Carica papaya, Magnifera indica, Psidium guajava, Vernonia amygdalina, Antioxidants, Malaria, DPPH, Oxidative stress. 


\section{INTRODUCTION}

Malaria is a global disease prevalent in the tropics caused by Plasmodium species. It is one of the oldest and greatest health challenges affecting $40 \%$ of the world's population. It affects 300-500 million people and kills 1.5-2.7 million people annually ${ }^{1}$. High mortality rate is reported in children and pregnant women, also the disease has a negative impact on the economy of prevalent countries $^{2}$. In Nigeria, malaria is endemic throughout the country. World health Organization (WHO) has estimated malaria mortality rate for children under five in Nigeria at 729 per $100,000^{3} \quad$ Nigeria's Ministry of Health reported in April 2004 that malaria is responsible for one out of ten deaths in pregnant women and costs the Federal Government of Nigeria over one billion naira annually ${ }^{3}$.

One of the major reasons for the development of anaemia in malaria seems to be oxidative stress $^{4-6}$. The immune system of the body is activated by infections, including malaria, thereby causing the release of reactive oxygen species. In addition to this, the malaria parasite also stimulates certain cells to produce reactive oxygen species thereby resulting in haemoglobin degradation ${ }^{5,7}$. Indeed, depressed level of plasma antioxidants has been shown in Plasmodium falciparum-infected children and it has been suggested as a possible contributor to the morbidity and mortality of malaria ${ }^{1}$.

Increased resistance of malaria parasites to the commonly used antimalarial drugs have been reported, and hence the need to intensify research in the area of development of new antimalarial drugs especially from medicinal plants. A review of the medicinal plants used in the southwestern part of Nigeria for the treatment of malaria indicates that a rich flora diversity exists in Nigeria ${ }^{8}$. The present study aims to investigate the free radical scavenging activities of some of the commonly used medicinal plants in southwestern Nigeria. The following plants were selected for investigation: $C$. papaya, $P$. guajava, $V$. amygdalina, and $M$. indica. The decoctions of the leaves of $C$. papaya, $P$. guajava, $V$. amygdalina and a decoction of the stem bark of $M$. indica are commonly used in the traditional treatment of malaria in southwestern Nigeria.

\section{MATERIALS AND METHODS}

\section{Collection and identification of plant materials}

Fresh leaves of $C$. papaya, $P$. guajava, $V$. amygdalina and the stem bark $M$. indica were collected from the premises of Lagos University Teaching Hospital, Lagos, Nigeria in January 2007. The plants were identified by $\operatorname{Dr}$ S.A. Adesegun of the Department of Pharmacognosy, Faculty of Pharmacy, University of Lagos, Lagos, Nigeria.

\section{Extraction of plant materials}

The plant materials (leaves of $C$. papaya, $P$. guajava, $V$. amygdalina and the stem bark of $M$. indica) were air-dried at room temperature $\left(26^{\circ} \mathrm{C}\right)$ for 2 weeks, after which it was grinded to a uniform powder. The ethanol extracts were prepared by soaking $100 \mathrm{~g}$ each of the dry powdered plant materials in $1 \mathrm{~L}$ of ethanol at room temperature for $48 \mathrm{~h}$. The extracts were filtered after $48 \mathrm{~h}$, first through a Whatmann filter paper No. $42(125 \mathrm{~mm})$ and then through cotton wool. The extracts were concentrated using a rotary evaporator with the water bath set at $40^{\circ} \mathrm{C}$. The percentage yield of extracts ranged from $7-19 \% \mathrm{w} / \mathrm{w}$.

\section{Phytochemical screening}

Phytochemical screening were perfomed using standard procedures ${ }^{9-10}$.

\section{Test for reducing sugars (Fehling's test)}

The aqueous ethanol extract $(0.5 \mathrm{~g}$ in $5 \mathrm{ml}$ of water) was added to boiling Fehling's solution ( $A$ and $B$ ) in a test tube. The solution was observed for a colour reaction.

\section{Test for anthraquinones}

$0.5 \mathrm{~g}$ of the extract was boiled with $10 \mathrm{ml}$ of sulphuric acid $\left(\mathrm{H}_{2} \mathrm{SO}_{4}\right)$ and filtered while hot. The filtrate was shaken with $5 \mathrm{ml}$ of chloroform. The chloroform layer was pipette into another test tube and $1 \mathrm{ml}$ of dilute 
ammonia was added. The resulting solution was observed for colour changes.

\section{Test for terpenoids (Salkowski test)}

To $0.5 \mathrm{~g}$ each of the extract was added $2 \mathrm{ml}$ of chloroform. Concentrated $\mathrm{H}_{2} \mathrm{SO}_{4}(3 \mathrm{ml})$ was carefully added to form a layer. A reddish brown colouration of the interface indicates the presence of terpenoids.

\section{Test for flavonoids}

Three methods were used to test for flavonoids. First, dilute ammonia $(5 \mathrm{ml})$ was added to a portion of an aqueous filtrate of the extract. Concentrated sulphuric acid $(1 \mathrm{ml})$ was added. A yellow colouration that disappear on standing indicates the presence of flavonoids. Second, a few drops of $1 \%$ aluminium solution were added to a portion of

the filtrate. A yellow colouration indicates the presence of flavonoids. Third, a portion of the extract was heated with $10 \mathrm{ml}$ of ethyl acetate over a steam bath for $3 \mathrm{~min}$. The mixture was filtered and $4 \mathrm{ml}$ of the filtrate was shaken with $1 \mathrm{ml}$ of dilute ammonia solution. A yellow colouration indicates the presence of flavonoids.

\section{Test for saponins}

To $0.5 \mathrm{~g}$ of extract was added $5 \mathrm{ml}$ of distilled water in a test tube. The solution was shaken vigourously.and observed for a stable persistent froth. The frothing was mixed with 3 drops of olive oil and shaken vigourously after which it was observed for the formation of an emulsion.

\section{Test for tannins}

About $0.5 \mathrm{~g}$ of the extract was boiled in $10 \mathrm{ml}$ of water in a test tube and then filtered. A few drops of $0.1 \%$ ferric chloride was added and observed for brownish green or a blue-black colouration

\section{Test for alkaloids}

$0.5 \mathrm{~g}$ of extract was diluted to $10 \mathrm{ml}$ with acid alcohol, boiled and filtered. To $5 \mathrm{ml}$ of the filtrate was added $2 \mathrm{ml}$ of dilute ammonia. 5 $\mathrm{ml}$ of chloroform was added and shaken gently to extract the alkaloidal base. The chloroform layer was extracted with $10 \mathrm{ml}$ of acetic acid. This was divided into two portions. Mayer's reagent was added to one portion and Draggendorff's reagent to the other. The formation of a cream (with Mayer's reagent) or reddish brown precipitate (with Draggendorff's reagent) was regarded as positive for the presence of alkaloids.

\section{Test for cardiac glycosides (Keller-Killiani test)}

To $0.5 \mathrm{~g}$ of extract diluted to $5 \mathrm{ml}$ in water was added $2 \mathrm{ml}$ of glacial acetic acid containing one drop of ferric chloride solution. This was underlayed with $1 \mathrm{ml}$ of concentrated sulphuric acid. A brown ring at the interface indicated the presence of a deoxysugar characteristic of cardenolides. A violet ring may appear below the brown ring, while in the acetic acid layer a greenish ring may form just above the brown ring and gradually spread throughout this layer.

\section{Determination of antioxidant activity}

The radical scavenging activities of the plant extracts against 2,2-Diphenyl-1-picryl hydrazyl radical (Sigma-Aldrich) were determined by UV spectrophotometry at $517 \mathrm{~nm}$. Radical scavenging activity was measured by a slightly modified method previously described $^{12,13}$. The following concentrations of the extracts were prepared, 0.05, 0.1, 0.5, 1.0, 2.0 and $5 \mathrm{mg} / \mathrm{ml}$ in methanol (Analar grade). Vitamins $\mathrm{C}$ was used as the antioxidant standard at concentrations of 0.02 , $0.05,0.1,0.2,0.5$ and $0.75 \mathrm{mg} / \mathrm{ml}$. I $\mathrm{ml}$ of the extract was placed in a test tube, and $3 \mathrm{ml}$ of methanol was added followed by $0.5 \mathrm{ml}$ of 1 $\mathrm{mM}$ DPPH in methanol. A blank solution was prepared containing the same amount of methanol and DPPH. The radical scavenging activity was calculated using the following formula:

$\%$ inhibition $=\left\{\left[A_{b}-A_{a}\right] / A_{b}\right\} \times 100$

where $A_{b}$ is the absorption of the blank sample and $A_{a}$ is the absorption of the extract 


\section{RESULTS}

\section{Phytochemical screening of plant materials}

The phytochemical screening of the plants studied showed the presence of flavonoids terpenoids, saponins and tannins (Table 1), $M$. indica, $V$. amygdalina and $P$. guajava showed the absence of anthraquinones. $M$. indica and $P$. guajava tested negative for the presence of alkaloids and only $M$. indica tested negative for the presence of cardiac glycosides (Table 1).

\section{Radical scavenging (antioxidant) activity}

$\mathrm{IC}_{50}$ of $0.04,0.31,0.58,2.30$ and $0.054 \mathrm{mg} / \mathrm{ml}$ were recorded for $P$. guajava, $M$. indica, $C$. papaya, $V$. amygdalina and Vitamin C, respectively (Figure 1 ).

\section{DISCUSSION}

Phytochemical screening of the plants revealed some differences in the constituents of the four plants tested. C. papaya tested positive for all the phytochemicals tested; $M$. indica showed the absence of anthraquinones, alkaloids and cardiac glycosides; $V$. amygdalina tested positive for all except anthraquinones while $P$. guajava tested positive for all except Anthraquinones and alkaloids. All the plants exhibited potent antioxidant activity. The presence of flavonoids and tannins in all the plants is likely to be responsible for the free radical scavenging effects observed. Flavonoids and tannins are phenolic compounds and plant phenolics are a major group of compounds that act as primary antioxidants or free radical scavengers ${ }^{14}$.

The DPPH test provides information on the reactivity of the test compounds with a stable free radical. DPPH gives a strong absorption band at $517 \mathrm{~nm}$ in visible region. When the odd electron becomes paired off in the presence of a free radical scavenger, the absorption reduces and the DPPH solution is decolourised as the colour changes from deep violet to light yellow. The degree of reduction in absorbance measurement is indicative of the radical scavenging (antioxidant) power of the extract. The crude extract of $P$. guajava appeared to be as potent as Vitamin $\mathrm{C}$ with a maximum inhibition of $91 \%$ at $0.5 \mathrm{mg} / \mathrm{ml}$ which is comparable to $95 \%$ for vitamin $\mathrm{C}$ at the

Table 1: Phytochemical constituents of $C$. papaya, M. indica, V. amygdalina and $P$. guajava

\begin{tabular}{lcccc}
\hline Test & C. Papaya & M. indica & V. amygdalina & P. guajava \\
\hline Reducing sugar & + & + & + & + \\
Anthraquinone & + & - & + & + \\
Terpenoids & + & + & + & + \\
Flavonoids & + & + & + & + \\
Saponins & + & + & + & + \\
Tannins & + & - & + & - \\
Alkaloids & + & - & + & + \\
$\begin{array}{l}\text { Cardiac } \\
\text { glycosides }\end{array}$ & + & & & + \\
\hline
\end{tabular}




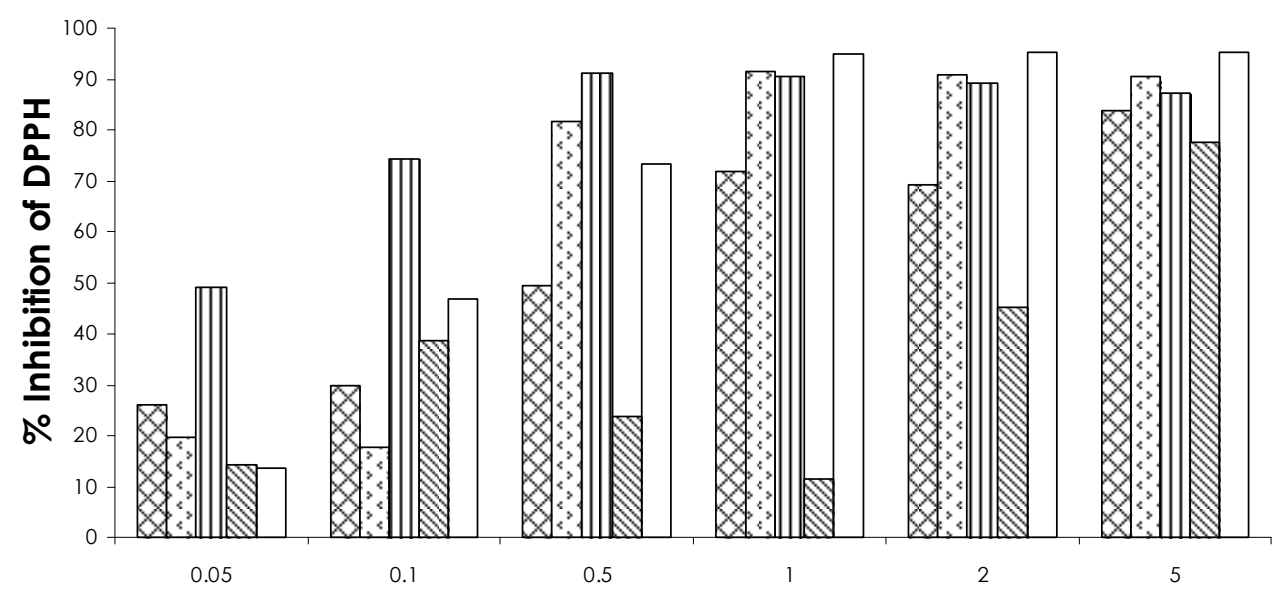

\section{Concentration $\mathrm{mg} / \mathrm{ml}$}

\section{曰.papaya \\ $\square$ M.indica \\ पP.guajava \\ Q V.amygdalina \\ $\square$ Vitamin C}

Figure 1: Inhibition of DPPH by the ethanolic extracts of C. papaya, M. indica, P. Guajava and V. Amygdalina, respectively.

same concentration. M. indica was six times less potent than the standard with a maximum inhibition of $91 \%$ at $1 \mathrm{mg} / \mathrm{ml}$, followed by $C$. Papaya which was eleven times less potent (than vitamin C) with a maximum inhibition of $83.8 \%$ at $5 \mathrm{mg} / \mathrm{ml}$. V. amygdalina was the least potent (42 times less potent than the standard) showing a maximum inhibition of $77.7 \%$ at $5 \mathrm{mg} / \mathrm{ml}$. This study suggests that these plants possess antioxidant activities which can counteract the oxidative damage induced by the malaria parasite. This may be one of their mode of action in malaria therapy.

\section{CONCLUSION}

Extracts from $C$. papaya, $M$. Indica, $V$. amygdalina and $P$. guajava showed varying antioxidant (free radical scavenging) activities when compared to vitamin $\mathrm{C}$ in the following order: $V$. amygdalina $<C$. papaya $<M$. indica $<$ Vitamin $\mathrm{C} \leq P$. guajava. The results suggest that the antioxidant activity of these plants may contribute to their claimed antimalarial property.

\section{ACKNOWLEGEMENT}

We thank Mr P. Ojobor of the Central Research Laboratory; Mr T.I. Adeleke of the Pharmacognosy Department; Mrs.Y.A. Bashorun, $\mathrm{Mr}$ Olatunji and $\mathrm{Mr}$ Olajide of Pharmaceutical Chemistry Department, all of the University of Lagos, for technical support. We also thank Ms J.O. Ashamu for assistance in the preparation of this manuscript.

\section{REFERENCES}

1. Nmorsi OPG, Ukwandu NCD Egwunyenga AO. Antioxidant Status of Nigerian Children with Plasmodium falciparum malaria. Afr. J. Microbial Res 2007; 61-64.

2. World Health Organization. Severe Falciparum malaria. Tran. R. Soc. Trop. Med. Hyg 2000; 94(Suppl 1): 51-590.

3. Government in action Report from presidential research and communication unit, office of puplic communication, State House, Abuja 2005.

4. Kulkarni AG, Suryakar AN, Sardeshmukh AS, Rathi $D B$. Studies on Biochemical Changes with Special Reference to Oxidant and Antioxidants in Malaria Patients. Ind. J. Clin. Biochem 2003; 18(2): 136-149. 
Ayoola et al

5. Das B.S, Nanada NK. Evidence for erythrocyte lipid peroxidation in acute falciparum malaria. Trans. Roy. Soc. Trop. Med. Hyg 1999; 93: 5862.

6. Kremsner PG, Greve B, Lell B, Luckner $D$ and Schmidt $D$. Malarial anaemia in African Children associated with high oxygen-radical production. Lancet 2000; 355: 40-41.

7. Loria $P$, Miller $S$, Foley $M$, Tilley $L$. Inhibition of peroxidative degradation of heme as the basis of action of chloroquine and other quinoline antimalarials. Biochem. J 1999; 339: 363-370.

8. Odugbemi TO, Odunayo RA, Aibinu IE, Fabeku, OP Medicinal plants useful for malaria therapy in Okeigbo, Ondo State, Southwest Nigeria. Afr. J. Trad. CAM. 2007; 4(2): 191-198.

9. Sofowora A. Medicinal plants and Traditional Medicine in Africa. Spectrum Books, Ibadan.
1993; pp 150.

10. Trease G.E., and Evans, W.C. Pharmacognosy. $13^{\text {th }}$ edn. Bailliere Tindall, London, 1989, pp 176180.

11. Harbone JB. Phytochemical Methods London. Chapman and Hall Ltd, 1973, pp49-188.

12. Brand-Williams W, Cuvelier ME, Berset C. Use of free radical method to evaluate antioxidant activity. Lebensmittel Wissenschaft und Technologie 1995; 28: 25-30.

13. Ayoola GA, Sofidiya T, Odukoya O, Coker H.A.B Phytochemical screening and free radical scavenging activity of some Nigerian medicinal plants. J. Pharm. Sci. \& Pharm. Pract. 2006; 8: 133-136.

14. Polterait $\mathrm{O}$. Antioxidants and free-radical scavengers of Natural Origin. Current Org. Chem. 1997; 1: $415-440$. 